\title{
Methods for investigating patterns of mortality and quantifying cause-specific mortality in sea-farmed Atlantic salmon Salmo salar
}

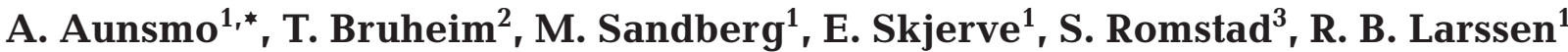 \\ ${ }^{1}$ Norwegian School of Veterinary Science, PO Box 8146 Dep, 0033 Oslo, Norway \\ ${ }^{2}$ National Veterinary Institute, Tungasletta 2, 7485 Trondheim, Norway \\ ${ }^{3}$ Norwegian Food Safety Authority, Verftsgata 48, 7800 Namsos, Norway
}

\begin{abstract}
Methods for investigating patterns of mortality and quantifying cause-specific mortality in Atlantic salmon Salmo salar farming were developed. The methods were further used to investigate mortality and patterns of mortality for the first 3 mo after sea transfer in the 2006 year-class autumn smolts ( $\mathrm{S} 0$ ) of Norwegian farmed Atlantic salmon. In the study population, which consisted of 20 pens at 10 sites, cause-specific mortality was examined by 11 fish health professionals during 8 visits to each pen. Cause-specific mortality proportions were used to convert crude mortality into cause-specific mortality. Cumulative mortality in the study period was $2.1 \%$ in the study population compared with $3.7 \%$ for the 2006 year-class S0s in the national database. Of this cumulative mortality, 73 and $59 \%$ took place in $20 \%$ of the pens in the study and the reference population, respectively. Daily mortality rates in the study population showed a variation from 0 to 2376 per 100000 fish where the majority of mortality was observed during disease outbreaks. All study pens had periods of low baseline mortality and some pens had no increased mortality during the study period. Of 2088 dead fish examined, 92\% (1929 fish) were assigned a specific cause of death, and in $97 \%$ of these 1929 fish the investigators reported the given cause of death to be likely or very likely. Ulcers were the main cause of death, accounting for $43 \%$ of the assigned mortality, and infectious agents were involved in $64 \%$ of the total mortality. The study shows that probable causes of death can be established in Atlantic salmon farming and their contribution to total mortality measured.
\end{abstract}

KEY WORDS: Salmo salar - Atlantic salmon - Mortality - Cause-specific mortality - Patterns of mortality

Resale or republication not permitted without written consent of the publisher

\section{INTRODUCTION}

The Norwegian government's statistics report that an average annual loss in sea-transferred salmon of $10.0 \%$ occurred in the period from 1994 to 2006 (Anonymous 2007a). Annual loss is estimated as the reported total number of fish lost during the year divided by total number of fish estimated to be present in the sea stock by January 1 plus the number of fish stocked during the year (Anonymous 2007a). This number is, however, biased by not accounting for the time during which the population is at risk. Hence, it does not take into account, for example, how the increasing use of autumn smolts enlarges the number present in the stock on 1 January. The benchmarking company MonAqua, which collects and compares Norwegian salmon production data, has documented an average loss of $15 \%$ per generation for cohorts in their database for the year-classes of 1998 to 2005, covering, on average, $17 \%$ of the Norwegian salmon industry (MonAqua AS: www.monaqua.com). In Scotland, the harvest percentage per year-class of sea-transferred salmon is reported to be, on average, $79.2 \%$, indicating a cumulated loss per year-class of $21 \%$ in the period of 1990 to 2002 (Anonymous 2005). All these data are of varying quality because of non-standardised registra- 
tions and inconsistencies in measures, making comparisons among companies, years and countries difficult. However, despite the inherent limitations, the loss at sea of farmed Atlantic salmon Salmo salar is substantial and represents a major economic challenge for the industry. A major part of the observed loss is caused by various diseases, representing a substantial portion of the cost of diseases in the salmon industry (Menzies et al. 2002, Brun et al. 2003, Olsen et al. 2007).

While some data are available for general mortality, statistics on cause-specific mortality are limited, and the methodology for estimating cause-specific mortality and costs of specific diseases is not standardised. In Norway, cause-specific statistics are restricted to the official statistics of number of outbreaks of the major infectious diseases, mainly being notifiable diseases (Olsen et al. 2007) or national statistics on losses categorised in crude blocks: mortalities, fish condemned at slaughter, escapees, counting errors and other causes (Anonymous 2007a). Studies of specific diseases often report disease-associated mortality (Jarp et al. 1995, Crockford et al. 1999, Brun et al. 2003, Rodger \& Mitchell 2007), a measure that may not represent the real cause behind the observed mortality. In Ireland, studies on cause-specific mortality indicate that gill disorders and pancreas diseases have been by far the leading causes of death in recent years (Rodger 2007).

Systematic data collection and analyses have been described for farmed Atlantic salmon (Menzies et al. 1996), and currently all salmon farming companies use sophisticated software programs as a tool in production control and inventory accounting. These programs facilitate the monitoring of health data, including cause-specific mortality. However, while daily mortality is usually well monitored, the lack of standardised methods for the estimation of cause-specific mortality, together with limited registrations by the producers, limits the use of such data. Providing accurate and extensive information for efficient decisions on animal health management may represent a substantial cost to the industry. However, studies have shown that relevant animal health measures may yield very high economic returns (Morris 1997).

This study was conducted in 10 Norwegian salmon farms with the following objectives: (1) to develop and validate methods for quantifying cause-specific mortality and investigating patterns of mortality in Atlantic salmon farming and (2) to use the developed methods to quantify causes and investigate patterns of mortality during the first 3 mo after sea transfer in selected Norwegian salmon pens.

\section{MATERIALS AND METHODS}

A pilot study was conducted in 2005 in 2 pens on 1 Atlantic salmon farm followed by similar studies on 9 farms in 2006. From the associated fish health services 11 investigators (fish health veterinarians and biologists) were recruited to investigate causes of death on 8 specific days during the first 3 mo after sea transfer.

Study population. The study population consisted of farmed Atlantic salmon in 20 pens at 10 commercial sites from Rogaland in the south to Troms in the north, geographically spread to represent all major Norwegian salmon farming counties. The counties of SørTrøndelag and Nordland had 2 sites each while Finnmark, the northernmost county, was not included since it had no autumn smolt (S0) production in 2006. Within counties sites were chosen by convenience, based on voluntary participation and their location within reasonable travel distance (Table 1). Two pens from the largest fish group, transferred to sea about the same time and preferably from different size grades, were included from each site. The fish, from either the Aqua

Table 1. Salmo salar and Oncorhynchus mykiss. Information about the study population and corresponding reference population of Atlantic salmon and rainbow trout in the national database

\begin{tabular}{|lcc|}
\hline & Study population & $\begin{array}{c}\text { National data } \\
\text { (reference population) }\end{array}$ \\
\hline Number of fish (millions) & 2.7 & 71.1 \\
Number of sites & 10 & 114 \\
Number of pens (mean no. fish per pen) & $20(139700)$ & $667(103100)$ \\
Species & Atlantic salmon & Atlantic salmon and rainbow trout \\
Sea transfer & 28 Aug-26 Nov 2006 & 1 Aug-31 Dec 2006 \\
Mean weight at sea transfer in grams (SD) & $81(25.8)^{\mathrm{b}}$ & $109.7(43.2)^{\mathrm{c}}$ \\
Location & Rogaland to Troms & Norway \\
Cumulative mortality first 3 mo $\left(\mathrm{CM}_{\text {cum_period }}\right)(\%)$ & 2.1 & 3.7 \\
${ }^{\mathrm{a}}$ In addition to the pilot study in 2005 & & \\
${ }^{\mathrm{b}}$ Mean weight at sea transfer & & \\
${ }^{\mathrm{c} M e a n}$ weight by end of first month at sea & & \\
\hline
\end{tabular}


Gen or Salmobreed strain, were stimulated to undergo parr-smolt transformation (smoltification) by the use of photoperiod manipulation within their first year (S0) and vaccinated with commercial intraperitoneal multivalent oil based vaccines prior to sea transfer.

Reference population. Norwegian fish farmers are by regulation required to report statistics, such as number of fish, mortality and fish size per cage, to a national database portal (Altinn) on a monthly basis. Data from this portal is further organized and redistributed to respective authority databases. Such data from the Norwegian food safety authorities fish health database (ANISTAT) were retrieved for fish stocked from 1 August until 31 December 2006 and used as the reference population for this study. A limitation to this dataset was the inclusion of sea-farmed rainbow trout Oncorhynchus mykiss without species-specific information. In 2006 rainbow trout accounted for $13 \%$ of the total of Norwegian sea-transferred salmon and trout smolts (Anonymous 2007b). Together with pens with missing mortality data, pens with fish exceeding an average weight of $150 \mathrm{~g}$ by the end of August were excluded, as these fish were most probably $1.5 \mathrm{yr}$ old smolts.

Population diagnostic work. Regulations require Norwegian salmon farmers to perform routine health inspections and investigate causes of death if daily mortality at the pen level exceeds $0.5 \%$ or an infectious disease is suspected. This can only be performed by defined professionals using appropriate laboratory tests. The National Veterinary Institute is the main laboratory for analysis of samples from disease outbreaks in Norway and offers a range of diagnostic tests (Anonymous 2007c). Normal procedures for the investigation of a population disease were followed for the study population. This included sampling and diagnosing moribund fish with the purpose of reaching a population diagnosis. Laboratory results from outbreak investigations at the study sites were retrieved from the National Veterinary Institute's database and compared with daily mortality patterns. The following methods were used for population diagnosis of disease: histopathology (infectious pancreatic necrosis [IPN], ulcers, piscirickettsiosis), immunohistochemistry (IPN, piscirickettsiosis) and bacteriology (ulcers). In addition other techniques such as cell culture and RT-PCR (for pancreas disease exclusion) were used in outbreak investigations. The results from the population diagnostic work were used as background knowledge for establishing a cause of death on individual fish.

Sampling dead fish. The investigators were asked to make 8 visits to their respective study pens at Weeks 1 , $2,3,5,7,9,11$ and 13 post sea transfer to conduct post mortem examinations of mortalities that occurred during the previous $24 \mathrm{~h}$. Fish autolysed to a degree where it interfered with the diagnostic work were excluded from the study. It was assumed that fish excluded because of autolysis were older and not representative of mortality in the previous $24 \mathrm{~h}$. At high mortality, a subsample of a minimum of 30 dead fish per pen was haphazardly retrieved and examined. For 10 pens the last visit was conducted in Week 14 instead of Week 13; these data are included in the study. A total of 156 pen visits were conducted with an average of 7.8 visits per pen. During the study period 2088 dead fish were examined, giving an average of 13.4 fish examined per pen visit.

Mortality data and cause of death. Crude mortality: Daily mortality was registered as the number of dead fish retrieved by the dead fish removal system. If dead fish were not retrieved for 1 or more days, the following day's mortality was evenly allocated between the days of non-retrieval. At 1 site the mortality data from 11 consecutive days were lost, but were later reproduced based on memory together with average mortality determined before and after the lost data. The stocking number was supplied by the fish farming companies, where fish are counted individually when vaccinated and subsequent mortalities found in the freshwater phase are later subtracted.

Cause of death of individual fish: Based on input from fish health services and experience from the pilot study, a predefined list of 19 categories for causes of death for use under field conditions was established for the study. This included 17 conditions that have the ability to cause death, 1 category for other causes and 1 category where no cause of death could be established. During the study, 2 of the diagnoses were split into 2 subdiagnoses each. The list was open and during the study period 1 cause of death was added (piscirickettsiosis), resulting in a final total of 22 categories.

At each visit individual dead fish were examined and, if possible, cause of death was determined. The investigators were asked to use all recent and historic relevant information in establishing the cause of death including their own experience, the freshwater history, site history, time and patterns of mortality, postmortem examination and laboratory diagnostic work on both population and individual dead fish. Histopathology was available for the study as a non-specific diagnostic tool in an attempt to increase the sensitivity of establishing the cause of death. A list with key points for each category including photographs of some conditions (unsmoltified, mechanical trauma, fin rot and ulcers) was made to standardise classification by the investigators. For further diagnostic work, we referred to the National Veterinary Institute's user handbook (Anonymous 2007c) and the textbook 'Fiskehelse og fiskesykdommer' (Poppe 1999). 
Likelihood of cause of death: The investigators, with an average experience in field diagnostic work with farmed Atlantic salmon of $9.8 \mathrm{yr}$, were asked to assess to what degree available information was sufficient to determine the specific cause of death on individual fish. The investigators were asked to grade the likelihood of the given cause of death being correct into 3 categories: (1) very likely, (2) likely or (3) the most likely of present differential diagnoses.

Assignment of cause-specific mortality: The proportions of the specific causes of death were calculated at the pen level for each pen visit conducted by the investigators. Daily pen level cause-specific mortality was calculated by multiplying the number of dead fish on each day $\left(n_{\text {crude_day }}\right)$ by the proportional mortality $\left(p_{\text {spec_day }}\right)$, using proportions found on the day of the closest investigator visit, thus giving an estimate of the number of fish dying from each given cause for each day in the pen ( $\left.n_{\text {spec_day }}\right)$.

Cumulative mortality: At the pen level, for both the study and reference populations, monthly cumulative crude mortality $\left(\mathrm{CM}_{\text {cum-month }}\right)$ was calculated as the proportion of registered dead fish found during the month compared with the number of fish in the unit at start of the month ( $\mathrm{n}_{0 \_ \text {month }}$ ) by means of the following formula with the time period being month:

$$
\begin{aligned}
\mathrm{CM}_{\text {cum_period }} & =n_{\text {crude_period }} \times n_{0}^{-1} \times 100 \% \\
& =\sum n_{\text {crude_day }(i)} \times n_{0}^{-1} \times 100 \%
\end{aligned}
$$

At the population level crude mortality was calculated both monthly and for the whole 3 mo study period using the same formula as for the pen level; this is equal to calculating the weighted average of the crude mortality in the pens using the number of fish at the start of the period as the weighting factor.

Mortality rates: For the study pens crude daily mortality rate $\left(\mathrm{MR}_{\mathrm{D}}\right)$ and cause-specific daily mortality rate $\left(\mathrm{CSMR}_{\mathrm{D}}\right)$ were calculated as mortalities per 100000 fish per day (Hammell \& Dohoo 2005), with the number at risk $\left(n_{\text {risk }}\right)$ being the number at the start of the period minus half the mortality during the time period (= midpoint population):

$$
\begin{aligned}
& \mathrm{MR}_{\mathrm{D}}=n_{\text {crude_day }} \times n_{\text {risk }}^{-1} \times 100000 \mathrm{~d}^{-1} \\
& \mathrm{CSMR}_{\mathrm{D}}=n_{\text {spec_day }} \times n_{\text {risk }}^{-1} \times 100000 \mathrm{~d}^{-1}
\end{aligned}
$$

Other study variables. Fork length was measured to the nearest $0.5 \mathrm{~cm}$ and weight was measured in grams for individually examined fish. The condition factor (CF) was calculated as follows:

$$
\mathrm{CF}=\text { weight }(\mathrm{g}) \times \text { length }(\mathrm{cm})^{-3} \times 100
$$

The running mean weight (MW) in the pen was estimated by the production steering programs by the use of mean weight at sea transfer and the daily feed and historical feed conversion ratios. MW for individual pens was registered on days of investigator visits; 1 site ( 2 pens) did not have any data on MW. The relative weight (RW) of dead fish was calculated as follows:

$$
\text { RW = weight }(g) \times M W(g)^{-1} \times 100
$$

Data management and statistical analysis. Data from individual investigators were delivered as Microsoft ${ }^{\circledR}$ Excel files. The data were quality controlled and checked with the investigators in cases of questionable or missing recordings. Pen level data from the national database (ANISTAT) was downloaded as a Microsoft ${ }^{\circledR}$ Excel file using inclusion and exclusion criteria as described. The datasets were further merged and analysed in STATA 9.2 (Stata) where tabular and graphical techniques were used to describe the data.

\section{RESULTS}

\section{Development and validation of methods}

$\mathrm{MR}_{\mathrm{D}}$ did effectively distinguish between epidemic and endemic patterns of mortality (see Fig. 2). At the pen level, all periods with increased mortality received a population diagnosis. For the infectious diseases this was confirmed by a laboratory diagnosis. At the fish level, 1929 (92.4\%) of 2088 dead fish examined were given a specific cause of death (Table 2). For $96.5 \%$ of the 1929 fish the investigators reported a likely or very likely cause of death (Table 3). Those fish examined and not given a specific cause of death $(7.6 \%)$ were found throughout the whole study period and pens. Histopathology on dead fish was partly inconclusive due to autolysis and did not significantly improve diagnosis of cause of death. Cause-specific mortality proportions were used to assign daily crude mortality to the 14 categories of cause-specific mortality reported in the study (Table 2). Time of death, CF and RW showed distinct cause-specific patterns (Table 3).

\section{Causes and patterns of mortality}

The crude cumulative mortality $\left(\mathrm{CM}_{\text {cum_period }}\right)$ was $2.1 \%$ in the study population compared with $3.7 \%$ in the national database for the first 3 mo after sea transfer. Of this mortality, 73 and $59 \%$ took place in $20 \%$ of the pens in the study and the reference population, respectively (Table 1, Fig. 1). In the 4 study pens with the highest mortality (at 3 sites), $\mathrm{CM}_{\text {cum_period }}$ was $8.6 \%$ compared with $0.2 \%$ in the 4 pens with lowest mortality (at 3 sites) (Fig. 2). Similarly, in the reference population, $\mathrm{CM}_{\text {cum_period }}$ was $9.4 \%$ in the $20 \%$ of pens with 
Table 2. Salmo salar. Causes of death and cause-specific proportions in the examined fish. Assigned cause-specific mortality and assigned cause-specific proportion in the whole study population during the 3 mo study period. IPN: infectious pancreatic necrosis

\begin{tabular}{|c|c|c|c|c|c|}
\hline Causes of death & $\begin{array}{l}\text { No. of pens } \\
\text { affected }\end{array}$ & $\begin{array}{l}\text { Post mortem } \\
\text { (no.) }\end{array}$ & $\begin{array}{l}\text { Post mortem cause- } \\
\text { specific proportion (\%) }\end{array}$ & $\begin{array}{c}\text { Assigned cause- } \\
\text { specific mortality (no.) }\end{array}$ & $\begin{array}{c}\text { Assigned cause- } \\
\text { specific proportion }(\%)\end{array}$ \\
\hline Unsmoltified & 11 & 117 & 5.6 & 3315 & 5.6 \\
\hline Precocious males & 4 & 69 & 3.3 & 1043 & 1.8 \\
\hline Mechanical trauma & 18 & 304 & 14.6 & 4276 & 7.3 \\
\hline Predator trauma & 12 & 55 & 2.6 & 761 & 1.3 \\
\hline Ulcers & 18 & 839 & 40.2 & 25338 & 43.0 \\
\hline Gill trauma & 3 & 21 & 1.0 & 814 & 1.4 \\
\hline Fin rot & 17 & 198 & 9.5 & 4680 & 7.9 \\
\hline Peritonitis & 6 & 22 & 1.1 & 429 & 0.7 \\
\hline Cachexia & 6 & 94 & 4.5 & 2201 & 3.7 \\
\hline IPN chronic ${ }^{\mathrm{a}}$ & 6 & 60 & 2.9 & 688 & 1.2 \\
\hline IPN acute ${ }^{b}$ & 5 & 79 & 3.8 & 3256 & 5.5 \\
\hline Piscirickettsiosis & 1 & 56 & 2.7 & 8380 & 14.2 \\
\hline Others & 7 & 15 & 0.7 & 192 & 0.3 \\
\hline No diagnosis & 18 & 159 & 7.6 & 3574 & 6.1 \\
\hline Total & 20 & 2088 & 100 & 58948 & 100 \\
\hline
\end{tabular}

Table 3. Salmo salar. The investigators' reported likelihood for establishing the correct cause of death in 1927 fish given a specific cause of death and the specific traits of each cause of death regarding mean (SD in parentheses) time of death since sea transfer, condition factor $(\mathrm{CF})$ and relative weight $(\mathrm{RW})$

\begin{tabular}{|c|c|c|c|c|c|c|}
\hline \multirow[t]{2}{*}{ Causes of death } & \multicolumn{3}{|c|}{ Likelihood for reporting correct cause of death } & \multicolumn{3}{|c|}{ Traits of specific causes of death } \\
\hline & $\begin{array}{l}\text { Very likely } \\
\text { (no.) }\end{array}$ & $\begin{array}{c}\text { Likely } \\
\text { (no.) }\end{array}$ & $\begin{array}{l}\text { Most likely of } \\
\text { differential } \\
\text { diagnosis (no.) }\end{array}$ & $\begin{array}{l}\text { Time of } \\
\text { death (d after } \\
\text { sea transfer) }\end{array}$ & $\mathrm{CF}$ & RW \\
\hline Unsmoltified & 80 & 36 & 1 & $12.1(13.7)$ & $1.21(0.27)$ & $46.6(18.8)$ \\
\hline Precocious males & 18 & 1 & 50 & $5.6(1.5)$ & $1.19(0.14)$ & $43.7(9.6)$ \\
\hline Mechanical trauma & 191 & 112 & 1 & $18.8(22.1)$ & $1.06(0.17)$ & $71,3(21.7)$ \\
\hline Predator trauma & 38 & 17 & 0 & $64.9(26.1)$ & $1.11(0.18)$ & $77.5(24.1)$ \\
\hline Ulcers & 810 & 28 & 1 & $39.6(21.7)$ & $1.08(0.18)$ & $58.3(18.9)$ \\
\hline Gill trauma & 19 & 1 & 1 & $29.1(21.8)$ & $1.01(0.15)$ & $80.2(20.1)$ \\
\hline Fin rot & 23 & 169 & 4 & $36.9(28.5)$ & $1.17(0.19)$ & $52.2(18.0)$ \\
\hline Peritonitis & 3 & 12 & 7 & $56.7(21.7)$ & $1.05(0.20)$ & $65.6(25.9)$ \\
\hline Cachexia & 8 & 86 & 0 & $65.4(18.8)$ & $0.70(0.23)$ & $16.9(13.7)$ \\
\hline IPN chronic & 14 & 46 & 0 & $53.0(22.1)$ & $0.75(0.17)$ & $15.3(10.4)$ \\
\hline IPN acute & 76 & 3 & 0 & $77.9(10.8)$ & $1.01(0.12)$ & $41.6(19.6)$ \\
\hline Piscirickettsiosis & 0 & 56 & 0 & $85.1(10.1)$ & $0.98(0.15$ & $67.9(24.3)$ \\
\hline Others & 12 & 1 & 2 & $52.1(25.4)$ & $1.08(0.14)$ & $59.6(13.5)$ \\
\hline No diagnosis $(\mathrm{n}=159)$ & & & & $43.3(27.7)$ & $1.08(0.17)$ & $69.7(25.3)$ \\
\hline Total & 1292 & 568 & 67 & & & \\
\hline Mean (SD) & & & & $39.0(28.0)$ & $1.06(0.21)$ & $56.7(24.3)$ \\
\hline
\end{tabular}

the highest mortality compared to $0.3 \%$ in the $20 \%$ of pens with the lowest mortality.

In the study population, at the pen level, $\mathrm{MR}_{\mathrm{D}}$ per 100000 fish showed a huge variation from 0 to 2376 , with a median $\mathrm{MR}_{\mathrm{D}}$ of 4.0 per 100000 fish d $\mathrm{d}^{-1}$ (Fig. 2). The majority of the mortality in the study took place in limited time periods in specific pens and by specific causes (Fig. 2). These peaks of mortality were mainly found to be due to a single cause per outbreak; however, minor secondary (or dual) causes were recorded within outbreaks as exemplified in Pen 19 (Fig. 3). A minor peak in mortality, associated with sea transfer, was seen in most pens (Fig. 2). Transfer associated causes of death were mainly unsmoltified fish, precocious males, mechanical trauma, ulcers and fin rot. All pens had periods of low baseline mortality and some pens had no periods of increased mortality at all during the study period (Fig. 2).

Ulcers were the largest single cause of death, accounting for $43.0 \%$ of total assigned mortality with 

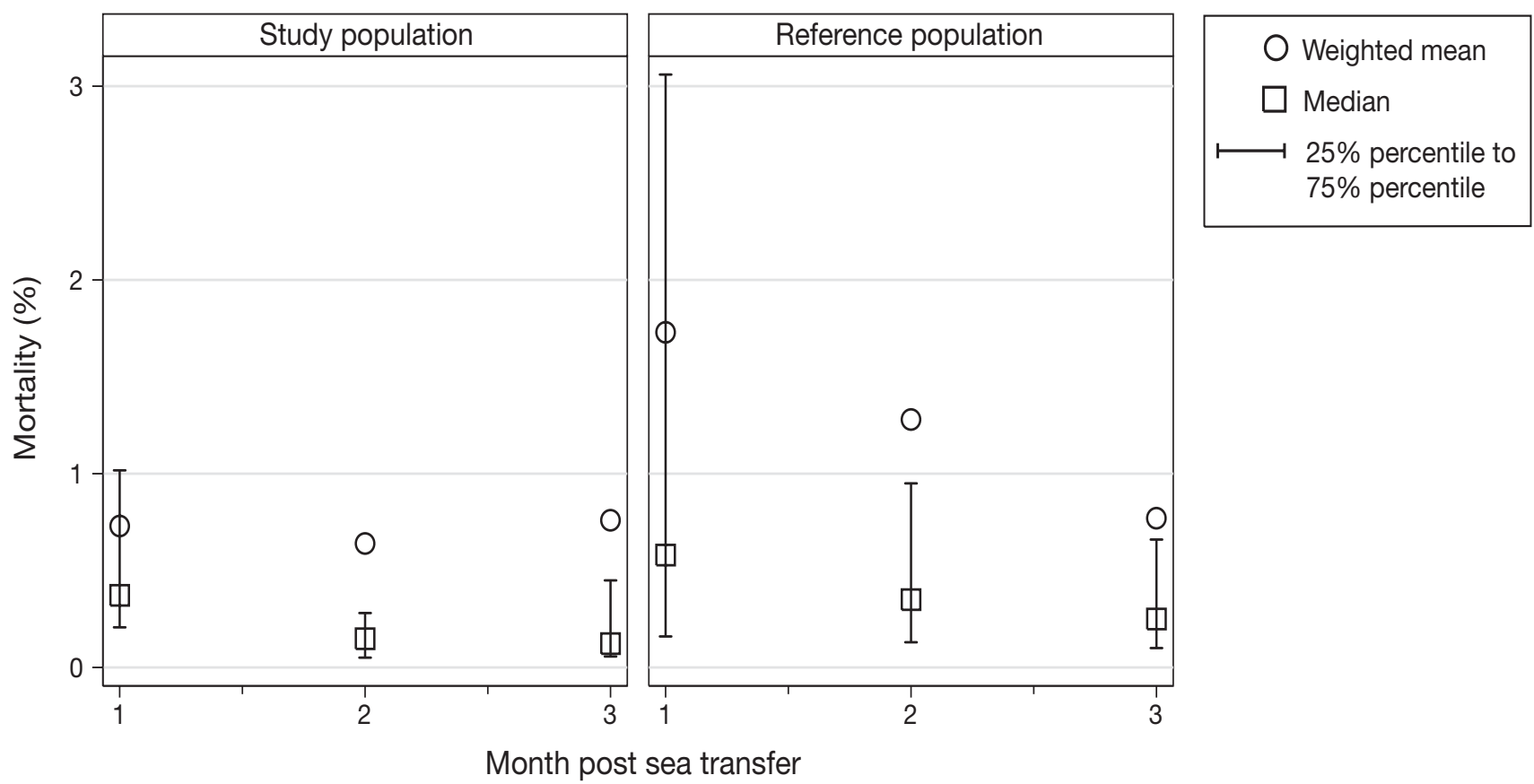

Fig. 1. Salmo salar and Oncorhynchus mykiss. Cumulative monthly mortality $\left(\mathrm{CM}_{\text {cum_month }}\right)$ at the pen level in the study population and the reference (national) population for autumn smolts of Atlantic salmon and rainbow trout in 2006 (S0) for the first 3 mo after sea transfer

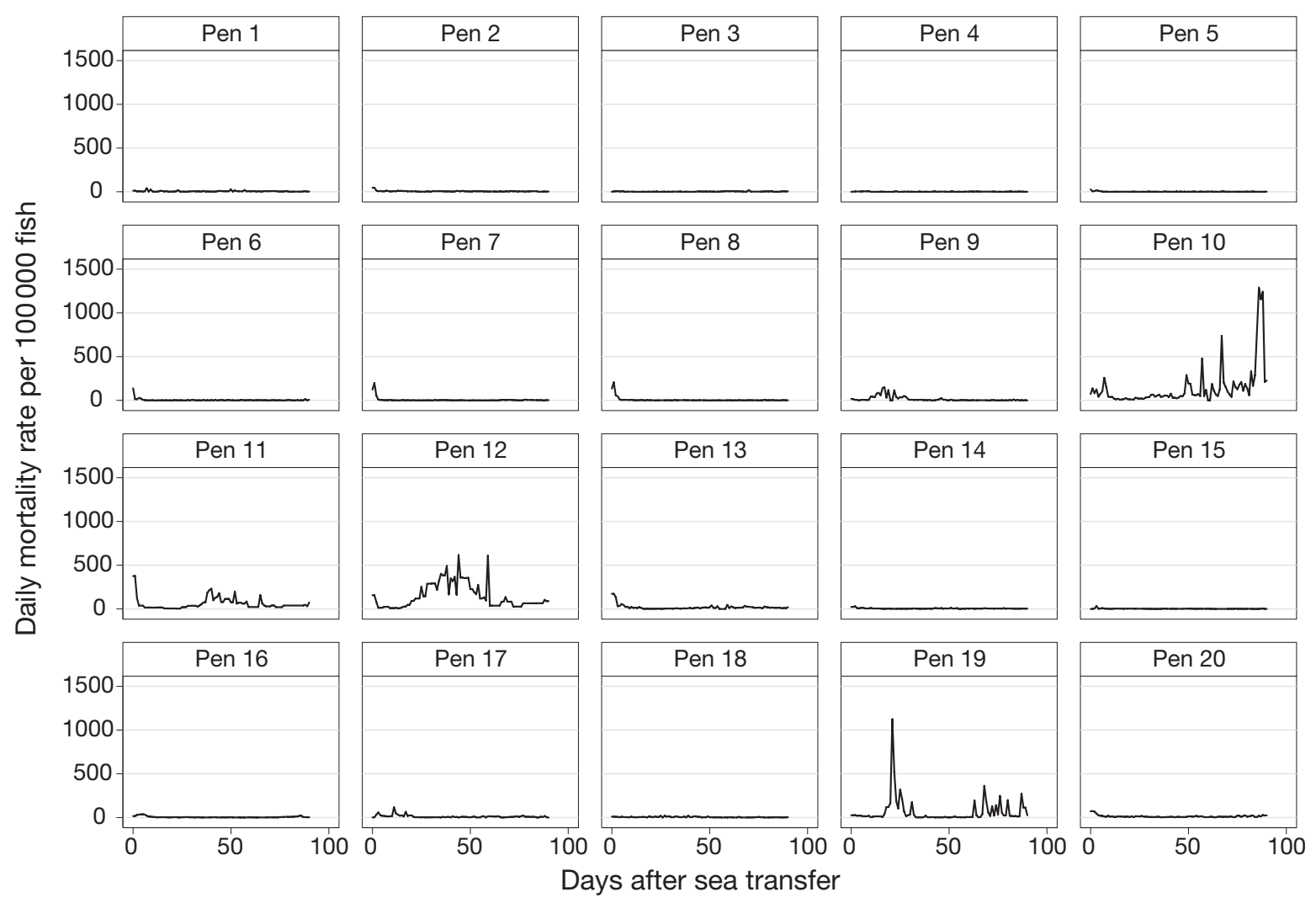

Fig. 2. Salmo salar. Daily mortality rates $\left(\mathrm{MR}_{\mathrm{D}}\right)$ per 100000 fish for the 20 study net pens during the first $90 \mathrm{~d}$ post sea transfer. In Pen 10, one day with a mortality rate of 2376 at the peak mortality is hidden in order to increase resolution of the graph 


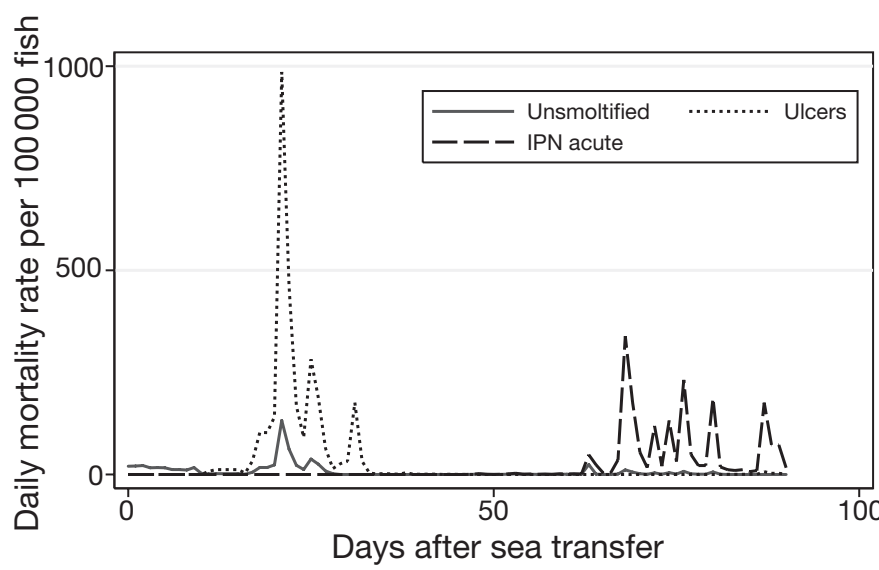

Fig. 3. Salmo salar. Assigned cause-specific daily mortality rates $\left(C S M R_{D}\right)$ for the leading causes of death in Pen 19. IPN: infectious pancreatic necrosis

outbreaks occurring in 5 pens. In 2 pens (Pens 11 and 12) with ulcer outbreaks, specific bacteria (Moritella viscosa and Vibrio wodanis) were found in kidney cultures. Non-specific Vibrio spp. was found in 3 pens, where ulcer mortality took place relatively early after sea transfer (Pens 9, 10 and 19). The causes of death involving infectious agents, such as ulcers, IPN and piscirickettsiosis, accounted for $63.9 \%$ of the total assigned mortality, where again mortality mainly took place in the same 5 pens and within time limited periods (Table 3, Fig. 2).

\section{DISCUSSION}

\section{Development and validation of methods}

In our study a limited number (12) of causes of death were sufficient for the investigators to adequately categorise cause of death in $92 \%$ of fish examined. Only 15 fish $(0.7 \%)$ were assigned a cause of death different from this final list. The inclusion of more pens and total period at sea will probably add more categories for cause of death; however, our findings suggest that the majority of mortality in Atlantic salmon farming can be categorised using a limited number of causes of death. Some categories, such as cachexia, fin rot and part of the ulcer category, most probably represent immediate causes of death and not the underlying cause. However, immediate causes are of interest, because they can help exclude other underlying causes with specific diagnostic criteria, and can point to the true underlying cause of death. Underlying and immediate causes may be present at the same time in specific pens, on different fish, making the extrapolation of knowledge of immediate causes of death into underlying causes of death possible.
The large number of dead fish occurring in the salmon industry will never be subjected individually to any advanced diagnostic procedures for accurate diagnosis of the cause of death. Quantification of cause-specific mortality must, therefore, rely on a system where information from a limited number of fish can be used for assigning crude mortality into causespecific mortality. Since laboratory work on dead fish often is unrewarding, clinical evaluation of causes of death is needed, thus giving the field fish health services a key role in systematic gathering of information on cause-specific mortality. Most diagnoses and, to a greater degree, establishing causes of death represent elements of subjective evaluation at the site or in diagnostic laboratories. Validity, therefore, will be a major concern in quantifying cause-specific mortality where both selection and misclassification may bias the results.

The investigators reported that their main diagnosis was the likely or very likely cause of death in $97 \%$ of fish given a cause; even at low mortality it was possible to establish likely specific causes of death. A total of $75 \%$ of fish in the lowest likelihood category was categorized to one cause of death, precocious males, classified by one investigator alone. This cause, however, had the earliest and most distinct time of death after sea transfer with a small standard deviation. Together with small standard deviations for CF and RW it can be argued that this probably was a specific causal entity, representing the true cause of death. In total the investigators seemed confident in establishing cause of death. These findings suggest that information is available to classify dead fish into causes of death with a reasonable compromise between sensitivity and specificity.

In our study most mortality took place as outbreaks, mainly represented by one leading cause of death per outbreak. With such a high prevalence, a large proportion of examined fish would be classified into the leading cause of death (high positive predictive value), even with a moderate sensitivity in the classification method. Thus, the dominating cause of death would be revealed by examining a relatively low number of fish. A high specificity would be important to avoid false positives that would otherwise overemphasize the importance of the true causes of death. However, in an outbreak situation, i.e. with one leading cause of death with a very high prevalence among the dead fish, fish detected with the leading cause would outnumber any other falsely detected cause of death.

Proportions of cause-specific mortality of examined dead fish in the study differed from proportions of assigned cause-specific mortality, as seen in Table 2. This is a mathematical consequence of the fact that the population level assigned mortalities are weighted 
measures (using $\mathrm{MR}_{\mathrm{D}}$ as a weighting factor) of the proportions of the examined dead fish. Since proportions in outbreaks should have more weight, the weighted data will be more valid for overall mortality proportions. Proportions found in examined fish, in comparison, will only be systematically biased towards proportions found in periods with low mortality. Representativeness of the proportional mortality, however, still remains as a possible error in the model assigning crude mortality into cause-specific mortality.

The study demonstrated great variation in mortality between sites and pens. This suggests that bias due to selection of pens and sites will be a major concern in studies describing mortality and cause-specific mortality in the Norwegian salmon production if based on samples that are too small and/or not representative. The study further suggests that sensitivity and specificity in establishing cause of death is reasonably good. Specific studies designed to investigate sensitivity, specificity and agreement between investigators for establishing causes of death are, however, needed to further elucidate these issues.

\section{Causes and patterns of mortality}

The level of mortality was reported to be lower than usual in several of the sites participating in the study. The general level was also lower than in the national database. The relatively small sample size and the convenience selection of sites with possible overrepresentation of well-managed sites may have added to the lower mortality level in the study population. In the study population the major portion of overall mortality took place as specific episodes, including both infectious and non-infectious causes of death. Curves of mortality rates showed epidemic patterns; in addition, very sharp mortality curves were seen, which suggests a single time point exposure (Klontz 1993). Some of the fish groups had, however, low baseline mortality throughout the study period and nearly all pens had periods with a low basal mortality. Similar patterns of mortality, although with less resolution, were seen in the national database with elevated mortality occurring during the first month after sea transfer, as described in Fig. 1. Here, both the weighted mean and the median for monthly cumulative mortality were found in the 25th to 75 th percentile interval, suggesting an elevated mortality in most pens. However, in Months 2 and 3 the weighted mean was outside this interval while the median was at the lower end, which suggests that the majority of mortality took place in a limited number of pens while most pens had relatively low mortality. This pattern was seen in both the study and the reference population (Fig. 1). Interestingly, the results show that it is possible to manipulate the smoltification process, and handle and transfer populations of close to 200000 smolts from fresh water into a marine environment without any noticeable increase in mortality. This finding suggests that there are specific risk factors contributing to both infectious and non-infectious causes of death. In the perspective of prevention, it may be possible to eliminate or control such episodes of increased mortality if risk factors are identified.

The cause-specific mortality showed involvement of infectious agents in the major outbreaks. Ulcers were the major cause of death seen both as part of the basal mortality in most pens and as outbreaks in 5 pens. In all ulcer outbreaks a combination of mechanical trauma together with bacteria was, in the investigators' view, considered as the mechanism of the outbreaks. IPN was seen as a major outbreak in 1 pen, as a minor mortality in 4 pens and also as mortality from chronic IPN damage caused by outbreaks in the freshwater phase. Minor non-infectious causes of death were, as judged by the causes, mainly related to management and handling and, for that reason, may offer an opportunity for control. Causes of death may be dual, as suggested in Pen 19 where 2 simultaneous peaks in causespecific mortality rates were seen (Fig. 3). The minor peak in mortality of unsmoltified fish was not expected $20 \mathrm{~d}$ after sea transfer. The different patterns of RW, along with the obvious differences in presence of ulcers and colouration, however, suggest there are reasons to categorise the mortalities into 2 groups. Unsmoltified fish may have been at special risk to the same factors that caused the large outbreak of ulcers, giving dual peaks in cause-specific mortality.

\section{Monitoring cause-specific mortality}

Health-monitoring systems in salmon farming may serve 3 purposes: (1) information for advice and decision-making by the producer, (2) information to the authorities and (3) research. The design of health-monitoring systems must take into account their objectives and their potential users. The rationale for grouping mortality into leading causes of death should, as in human medicine, have an epidemiological basis that is associated with the idea of implementing control measures (Becker et al. 2006). In corporate decisions regarding fish health, economical considerations are often involved, requiring quantitative description of fish health status that can be converted into monetary values. Total weight of dead fish combined with causespecific cumulative mortality may be converted to monetary loss, thereby making decisions and priorities for mortality management possible. Crude cumulative and especially cause-specific cumulative mortality 
data will also be valid as measures for comparison and surveillance of mortality in pens, sites, years and countries for corporations as well as for authorities and for research purposes. $\mathrm{MR}_{\mathrm{D}}$ give additional valuable information when investigating mortality patterns, compared with cumulative mortality data only, for example, to distinguish between epidemic and endemic mortality. In risk factor studies using cause-specific mortality rate and also in survival analysis, the methods require $\mathrm{CSMR}_{\mathrm{D}}$ for defining the outcome variable. All these measures can be calculated by monitoring $\mathrm{MR}_{\mathrm{D}}$ together with proportional mortality. Current systems for monitoring $\mathrm{MR}_{\mathrm{D}}$ are considered to be good, while systems for establishing proportional mortality do require development.

\section{CONCLUSION}

The study shows that grouping fish mortality in Atlantic salmon farming under field conditions into likely causes of death is both possible and feasible, and that this potentially useful information can be made available. The baseline mortality can be very low and our results suggest that the major portion of mortality takes place during episodes, dominated by infectious causes of death.

Acknowledgements. The authors thank the contributors who made this study feasible: SalMar, Marine Harvest, PanFish, Leroy Midnor, Fjord Seafood, Mainstream, Langøylaks, Firda Sjøfarmer, Flakstadvåg Laks, The Fishery and Aquaculture Industry Research Fund and The Norwegian Research Council. Special thanks go to all the investigators who participated in the study: S. Sværen, H. Aase, A. A. Asheim, T. M. Haugland, L. B. Rønneberg, M. Halse, H. Romstad, A. Nilsen, K. V. Nielsen and P. A. Sæther.

\section{LITERATURE CITED}

Anonymous (2005) Scottish fish farms annual production survey, 2004. Fisheries Research Services Marine Laboratory, Aberdeen

Editorial responsibility: Carl Schreck, Corvallis, Oregon, USA
Anonymous (2007a) Statistics for the Norwegian aquaculture industry. Directorate of Fisheries, www.fiskeridir.no, accessed 22 August 2007

Anonymous (2007b) Statistics for aquaculture 2006 (in Norwegian). Directorate of Fisheries, Bergen

Anonymous (2007c) The National Veterinary Institute user handbook. www.vetinst.no

Becker R, Silvi J, Ma Fat D, L'Hours A, Laurenti R (2006) A method for deriving leading causes of death. Bull World Health Organ 84:297-304

Brun E, Poppe T, Skrudland A, Jarp J (2003) Cardiomyopathy syndrome in farmed Atlantic salmon Salmo salar: occurrence and direct financial losses for Norwegian aquaculture. Dis Aquat Org 56:241-247

Crockford T, Menzies FD, McLoughlin MF, Wheatley SB, Goodall EA (1999) Aspects of the epizootiology of pancreas disease in farmed Atlantic salmon Salmo salar in Ireland. Dis Aquat Org 36:113-119

Hammell KL, Dohoo IR (2005) Mortality patterns in infectious salmon anaemia virus outbreaks in New Brunswick, Canada. J Fish Dis 28:639-650

Jarp J, Gjevre AG, Olsen AB, Bruheim T (1995) Risk-factors for furunculosis, infectious pancreatic necrosis and mortality in post-smolt of Atlantic salmon, Salmo salar L. J Fish Dis 18:67-78

Klontz GW (1993) Epidemiology. In: Stoskopf MK (ed) Fish medicine. WB Saunders, Philadelphia, PA, p 210-220

Menzies FD, McLoughlin M, Wheatley SB, Goodall EA (1996) Development of a computerized information retrieval system for Atlantic salmon, Salmo salar L., production. Aquac Res 27:183-190

Menzies FD, Crockford T, Breck O, Midtlyng PJ (2002) Estimation of direct costs associated with cataracts in farmed Atlantic salmon (Salmo salar). Bull Eur Assoc Fish Pathol $22: 27-32$

Morris RS (1997) How economically important is animal disease and why? In: Dijkhuizen AA, Morris RS (eds) Animal health economics. University of Sydney, p 1-11

Olsen AB, Bornø G, Colquhoun DJ, Flesjå K and others (2007) Diseases in farmed salmonids 2006. National Veterinary Institute, Oslo

Poppe T (1999) Fiskehelse og fiskesykdommer. Universitetsforlaget, Olso

Rodger HD (2007) Gill disorders: an emerging problem for farmed Atlantic salmon (Salmo salar) in the marine environment. Fish Vet J 9:38-48

Rodger H, Mitchell S (2007) Epidemiological observations of pancreas disease of farmed Atlantic salmon, Salmo salar L., in Ireland. J Fish Dis 30:157-167

Submitted: September 18, 2007; Accepted: June 20, 2008 Proofs received from author(s): August 7, 2008 